Review

\title{
Is narcolepsy a classical autoimmune disease?
}

\author{
María-Teresa Arango ${ }^{a, b, c}$, Shaye Kivity ${ }^{\mathrm{a}, \mathrm{d}, \mathrm{e}}$, Yehuda Shoenfeld ${ }^{\mathrm{a}, \mathrm{f}, \mathrm{g}, *}$ \\ a Zabludowicz Center for Autoimmune Diseases, Sheba Medical Center, Tel-Hashomer, Affiliated to Sackler Faculty of Medicine, Tel Aviv University, Israel \\ b Center for Autoimmune Diseases Research - CREA, Universidad del Rosario, Bogota, Colombia \\ ${ }^{c}$ Doctoral Program in Biomedical Sciences, Universidad del Rosario, Bogota, Colombia \\ ${ }^{\mathrm{d}}$ Rheumatic Disease Unit, Sheba Medical Center, Tel-Hashomer, Israel \\ e The Dr. Pinchas Borenstein Talpiot Medical Leadership Program 2013, Sheba Medical Center, Tel-Hashomer, Israel \\ ${ }^{\mathrm{f}}$ Sackler Faculty of Medicine, Tel-Aviv University, Israel \\ ${ }^{g}$ Incumbent of the Laura Schwarz-Kip Chair for Research of Autoimmune Diseases, Tel Aviv University, Israel
}

\section{A R T I C L E I N F O}

\section{Article history:}

Received 15 October 2014

Accepted 17 October 2014

Available online 29 October 2014

\section{Keywords:}

Narcolepsy

Autoimmune diseases

ASIA syndrome

Adjuvant

Infections

H1N1

\begin{abstract}
A B S T R A C T
Narcolepsy is a neurological disorder characterized by excessive daytime sleepiness. It is caused by the loss of orexin producing neurons in the lateral hypothalamus. Current evidences suggest an autoimmune mediated process causing the specific loss of orexin neurons. The high association of the disease with the HLA DQB1*06:02, as well as the link with environmental factors and are important clues supporting this theory. Recently, the association between the occurrence of the disease and vaccination campaign after the $2009 \mathrm{H} 1 \mathrm{~N} 1$ pandemic highlighted the importance to increase the knowledge in the Pandora box of the vaccines. This review discusses the last finding regarding the pathogenesis of the disease and its relationship with the H1N1 vaccines.
\end{abstract}

(C) 2014 Elsevier Ltd. All rights reserved.

\section{Contents}

Introduction

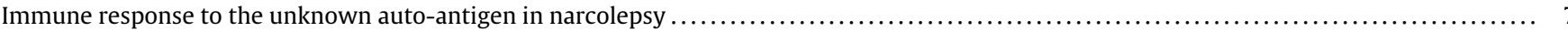

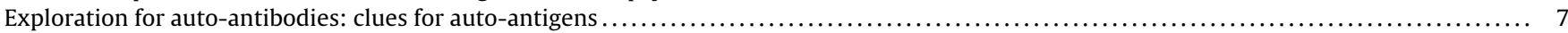

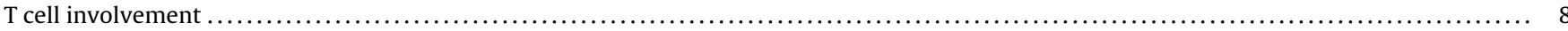

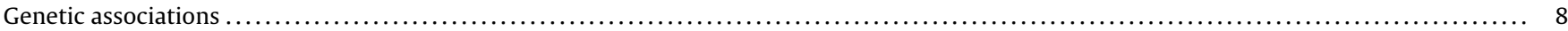

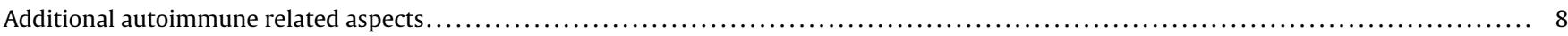

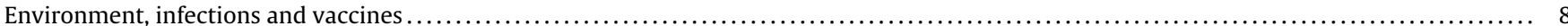

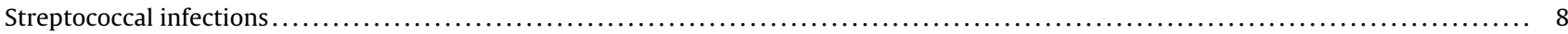

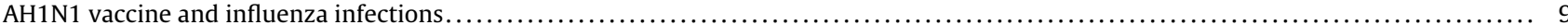

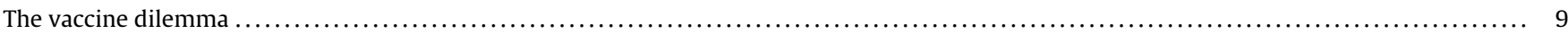

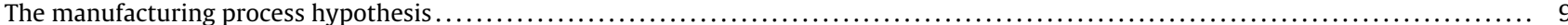

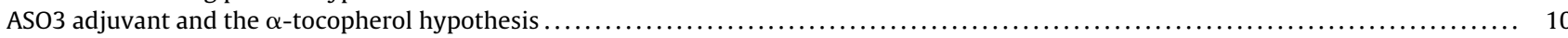

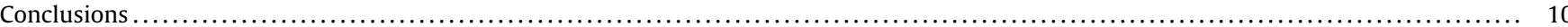

Competing interests

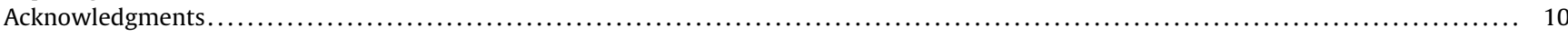

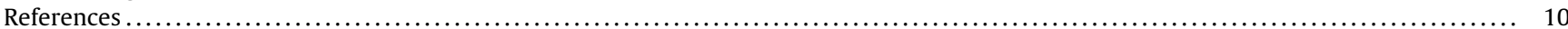

Abbreviations: ASIA, autoimmune/autoinflammatory syndrome induced by adjuvants; REM, rapid eye movement; ICSD-3, International Classification of Sleep Disorders

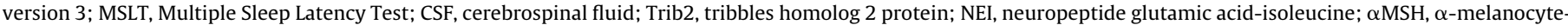

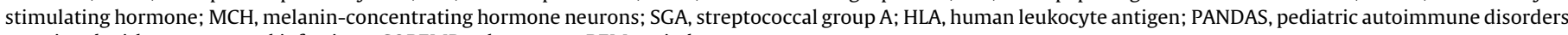
associated with streptococcal infections; SOREMPs, sleep onset REM periods.

* Corresponding author at: The Zabludowicz Center for Autoimmune Diseases, Chaim Sheba Medical Center, Tel-Hashomer 52621, Israel. Tel.: +972 3 5308070; fax: +97235352855 .

E-mail address: shoenfel@post.tau.ac.il (Y. Shoenfeld). 


\section{Introduction}

Autoimmune diseases are chronic inflammatory conditions which can be organ specific or systemic. They are initiated by the loss of immunological tolerance to self-antigens. Their pathogenesis involved both intrinsic (e.g. genetic, epigenetic) and environmental factors (e.g. infections, vaccines, adjuvants). In 2011, Shoenfeld and Agmon-Levin described the Autoimmune/autoinflammatory syndrome induced by adjuvants (ASIA) to summarize the spectrum of immune-mediated diseases and symptoms triggered by an adjuvant stimulus [1,2]. In addition, they detailed a collection of data demonstrating the association between different vaccines and autoimmune diseases [1,2]. In particular, influenza vaccine has been related with systemic lupus erythematosus, rheumatoid arthritis, vasculitis, reactive arthritis and Guillain Barré syndrome [3]. Interestingly, after the declaration of a global H1N1 influenza pandemic an impressive amount of evidence linked the vaccination campaign with an increment in the number of cases of narcolepsy in Europe [4].

Narcolepsy is a sleep disorder characterized by excessive sleepiness daytime. It is considered a rare disease with world prevalence between 25 and 50 per 100,000 people [5]. However, its prevalence varies from one country to another highly depending on the genetic background of the population. For instance, the lowest has been reported in the middle east, being $0.23 / 100,000$ in Israeli Jewish population [6] and in Saudi Arabia 4/100.000 [7] while Japan presents the highest reported up to 160/100,000 [8]. According to the International Classification of Sleep Disorders version 3 (ICSD-3), this disease is characterized by uncontrollable rapid eye movement (REM) attacks in which the previous non-REM stage is absent. In addition, patients may present other symptoms such as cataplexy (loss of muscle tone), disrupted nocturnal sleep, sleep paralysis, hallucinations and obesity [9,10]. In 2014, the ICSD-3 criteria established that narcoleptic type 1 patients (orexin deficiency) must present daily periods of irrepressible need to sleep or daytime lapses into sleep. Furthermore, they must meet at least one of the following characteristics. First, presence of cataplexy and the sleep tests should show mean sleep latency up to 8 min or to have two or more sleep onset REM periods (SOREMPs) on a Multiple Sleep Latency Test (MSLT) under standard conditions. Second, the levels of orexin 1 cerebrospinal fluid (CSF) should be less than $110 \mathrm{pg} / \mathrm{mL}$ or $1 / 3$ of mean values lower than the mean obtained in normal subjects with the same immuno-reactive standardized assay [11].

In narcolepsy, the specific group of neurons in charge of orexin production is loss, which is a neurotransmitter involved in different metabolic process. This resembles the specific destruction of insulin-producing $\beta$-cells in the pancreas of patients with diabetes mellitus type $1[12,13]$. Therefore, narcolepsy has been considered an autoimmune disease. Orexin absence inhibits the ability to regulate the sleep-arouse balance, resulting in sleep disturbances $[14,15]$. The orexin levels in the CSF are low or undetectable compared with healthy individuals as consequence of the absence of these neurons [9,15]. According to Rose revision of Witebsky's postulates, five criteria are necessary to recognize an autoimmune disease [16]. Initially, the identification of the auto-antigen(s) involved in the disease is necessary; followed by the identification and isolation of auto-antibodies or auto-reactive T cells. This will allow the inoculation of the antigen with adjuvant in naïve animals inducing the progression of the disease and the appearance of $\mathrm{T}$ reactive cells or auto-antibodies. Consequently, the passive transfer of $\mathrm{T}$ cell or antibodies from the sick in to naïve animals should replicate the disease. Finally, additional circumstantial evidence such as genetic association and environmental triggers of autoimmune mediated process among others should be considered $[2,16,17]$. In this review, we will examine evidences supporting an autoimmune origin of narcolepsy, as well as the emerging concepts regarding the association between narcolepsy and environmental factors.

\section{Immune response to the unknown auto-antigen in narcolepsy}

The identification of specific auto-antigen(s) is a key factor to unravel the autoimmune process of a particular disease. It is expected that the discovery of the auto-antigen(s) will allow the understanding of the mechanisms which are altered in the disease. In narcolepsy the auto-antigen has not yet been identified, rendering impossible an active immunization to induce an animal model. Moreover, some authors reported higher levels of inflammatory cytokines (i.e. G-CSF and IL-8) in the plasma of narcoleptic patients [18] and altered cytokine profile in patients with narcolepsycataplexy compared to controls, particularly involving IL-4 and significant Th1/Th2 imbalance [19]. However, no inflammatory process, including lymphocytic infiltration has been observed in the hypothalamus during post-mortem brain analysis of long-term disease patients $[20,21]$. It is noteworthy that the impossibility to analyze the brain of patients in early stages is a major obstacle $[4,22,23]$.

\section{Exploration for auto-antibodies: clues for auto-antigens}

The presence of auto-antibodies is a main characteristic of autoimmune diseases. Therefore, in order to find evidence for the autoimmune etiology of narcolepsy some studies have searched the presence of specific auto-antibodies. Passive transfer of antibodies from narcoleptic patients to murine models has demonstrated either sleep behavioral disturbances or brain histological changes [24]. Moreover sera from narcoleptic patients can bind brain or muscle structures $[4,25]$. However, the specific mechanisms by which the antibodies are inducing these changes are still unknown. So far, some attempts to identify a possible auto-antigen have been done base on the analysis of the specificity of antibodies from narcoleptic patients.

In 2010, Cvetkovic-Lopes et al., described the presence of antibodies against Tribbles 2 (Trib2) in narcoleptic patients, which bound orexin producing neurons in mouse brains [26]. These autoantibodies were described originally in uveitis (11) and they were found to have higher titers in a small group of narcoleptic patients (14\%) when they were compared with healthy controls [26-28]. Total IgG from narcoleptic patients (confirmed to be anti-Trib2 positive) was intra-ventricular brain injected in naïve mice. This induced narcoleptic-like attacks similar to those observed in narcoleptic patients as well as loss of orexin producing neurons in the lateral hypothalamus of the injected mice, as well as behavioral and cognitive changes [24]. Moreover, the animals injected with IgG from narcoleptic patients had also loss of NeuN (neuronal marker), and synaptophysin (synaptic marker) which did not necessarily correspond to the same spots where the orexin neurons are located. This may indicate that the antibodies can have also effects on other groups of neurons contributing to the changes observed in the animals. This study reported for the first time the importance of humoral response in narcolepsy [24]. Despite this association there is no clue about the involvement of anti-Trib2 in the disease, since Trib2 is not reported to be involved in a process specifically associated with orexin or sleep [29,30]. Indeed, just one report indicates that this Trib-2 may be associated with brain processes as it is highly express in female mice with anxiety, yet a specific mechanism linking it with narcolepsy has not been described [31].

A recent study also found that passive transfer of IgG from narcoleptic patients in rat brains induced changes in different 
sleep parameters. Three different patterns in which sera of narcoleptic patients can bind to brain rat tissue were identified. In the first pattern, antibodies bound mainly hypothalamic melaninconcentrating hormone and pro-opiomelanocortin but not orexin neurons. In the second pattern, GABAergic cortical interneurons were recognized by the antibodies. In the last pattern antibodies mainly bound globus pallidus neurons. Interestingly, a more detailed analysis of the first pattern showed that antibodies recognized a common C-terminal epitope in the neuropeptide glutamic acid-isoleucine (NEI) and the $\alpha$-melanocyte-stimulating hormone $(\alpha \mathrm{MSH})$ peptides. These two molecules are present in the hypothalamic in the melanin-concentrating hormone neurons $(\mathrm{MCH})$ but not in orexin producing neurons [32]. These results contrast Cvetkovic-Lopes report who showed that sera from patients can bind orexin producing neurons [26]. Unlike anti-Trib2 the presecence of antibodies to MSH expresing neurons can potentially interfer in the process associated with narcolepsy, since MSH neurons can moduluate orexin neurons functions [33,34].

\section{T cell involvement}

In 2013, an exciting report suggested orexin to be an auto-antigen. Functional analyzes of $\mathrm{CD} 4^{+}$lymphocytes from narcoleptic patients showed that these cells were able to recognize orexin peptides presented by dendritic cells (homozygotic for DQA $1 * 01: 02 / D Q B 1 * 06: 02$ haplotype). Moreover, those cells could also recognize peptides from $\mathrm{H} 1 \mathrm{~N} 1$ indicating a possible molecular mimicry between orexin and similar peptides from H1N1. This may partially explain the relationship described between the H1N1 vaccine and narcolepsy (See Sections "AH1N1 vaccine and influenza infections" and "The vaccine dilemma") [35]. However, the authors were not able to replicate the results leading to the retraction of the paper [36,37]. It is to note that the original paper still demonstrated structural similarities between orexin peptides and the haemaglutinin 1 employed for the elaboration of the vaccine which can be further explored.

\section{Genetic associations}

One of the common characteristics of autoimmune diseases is to be frequently associated with specific HLA. The strongest evidence that narcolepsy has an autoimmune etiology comes from genetic studies. Several studies demonstrated that narcolepsy is highly associated with HLA risk polymorphisms, in particular DQB1*06:02 and DQA $1^{*} 01: 02$. The higher risk is reported for DQB1*06:02 carriers as it is present in $82-99 \%$ of narcoleptic patients $[38,39]$, while only $12-38 \%$ of healthy individuals have this allele. Indeed, homozygote individuals for DQB1*06:02 have an increased risk to develop narcolepsy [38-40]. Other polymorphic associations have been described with other genes such as tumor necrosis factor alpha [9], tumor necrosis factor (ligand) superfamily member 4, T cell receptor alpha chain [41], Cathepsin H, DNA methyltransferase I $[42,43]$, among others [44]. Of note, many of the polymorphisms are in immune related genes supporting the hypothesis of an immunemediated mechanism which may involve antigen presentation, including lymphocyte sub-populations as well as antigen presenting cells [23].

\section{Additional autoimmune related aspects}

Due to the common mechanisms in autoimmune diseases [17], the presence of more than one autoimmune disease in one patient is common [45]. A study in a Spanish cohort showed that approximately $16 \%$ of the narcoleptic patients had one or more immunopathological disorders including allergies and autoimmune diseases, such as systemic lupus erythematosus and multiple sclerosis. In addition, familial autoimmunity was recently demonstrated to be a frequent condition [46]. In the case of narcolepsy, first degree relatives of patients have a higher risk to develop the disease $[47,48]$, supporting the importance of genetic background. However, twin studies demonstrated that the concordance rate of narcolepsy in monozygotic twins is $20-35 \%$ suggesting that the development of the disease does not depend only on the genetic background but also on environmental factors [48].

\section{Environment, infections and vaccines}

In genetically susceptible individuals autoimmune diseases can be triggered by exposure to external molecules or factors. As mentioned above, the concordance rate of narcolepsy in twins indicates the importance of environmental factors. Interestingly, the age of onset in narcolepsy is frequently at teenage suggesting that hormonal changes in puberty might trigger the disease [8,49-52]. Few reports regarding the exposure to toxic substances have been done. For example, one study comparing narcoleptic patients with a group of match controls showed that exposure to heavy metals, woodwork, fertilizers and pesticides are a risk for narcolepsy in a particular population [53]. Passive smoking has also been related with the onset of the disease in HLA DQB1*06:02 carriers [54]. In addition, other external stressors such as major changes in sleeping habits or changes in living style, carried out an additional risk [52]. Unfortunately, all this evidence is limited to small cohorts and specific populations making necessary to clarify the role of these factors in the development of the disease. Nevertheless, the strongest and most discussed evidence regarding environmental factors and narcolepsy is the association with infections and vaccination.

In 2007, the medical records analyses of narcoleptic DQB1*06:02 carriers and matched controls as well as the evaluation of detailed questionnaires demonstrated the importance of infectious agents. Thus, measles infection and the presence of unexplained fever in the past history were reported to be associated with higher risk of developing subsequently narcolepsy [52]. It is widely recognized that infections can induce autoimmunity through different mechanisms, such as molecular mimicry, epitope spreading, bystander activation and superantigens [55-59]. In the narcolepsy scenario, it has been suspected that streptococcal and influenza A infections as well as the H1N1 vaccine play a role in the pathogenesis of the disease [60-62].

\section{Streptococcal infections}

The importance of streptococcal group A (SGA) infection in autoimmunity has been extensively studied. The molecular mimicry between SGA and human proteins helps to the progression of immune-mediate damage which may involve heart, joints, skin and brain as a consequence of antigen mimicry with $\mathrm{M}$ - protein (40). Moreover, the production of superantigens by SGA can also stimulate auto-reactive $B$ and $T$ cells leading to the production of autoantibodies $[63,64]$. High anti-streptococcal antibodies were detected in the sera of newly diagnosed narcoleptic patients close to the onset of the disease [60]. Consequently, the analysis in narcolepsy patients and matched control carriers of HLA DQB1*06:02 concluded that childhood streptococcal throat infection was a risk factor for narcolepsy when it compared childhood infectious diseases, such as mononucleosis, pneumonia, or hepatitis [65]. An interesting example was described in 2013, when an eight year old child positive for DR2 (DR 15) and HLA DQB1*0602 was diagnosed with Sydenham Chorea and narcolepsy. Interestingly, besides the HLA this patient had CSF orexin deficiency and elevated titers of anti-streptococcal antibodies (i.e. anti-streptolysin O) [65]. It is important to highlight that SGA infections have also been related 
with neurological conditions other than narcolepsy. Indeed, Sydenham chorea syndrom, pediatric autoimmune disorders associated with streptococcal infections (PANDAS) and different dystonias have been described following this infection [63,66-68]. Of note, the association is not only with the infection itself but also with the presence of auto-antibodies against neuronal proteins including neuronal receptors which can alter signaling pathways, such as CaMKII, tyrosine hydroxylase with eventual dopamine release or the direct stimulation of dopamine receptors [66-71].

\section{AH1N1 vaccine and influenza infections}

A recent report summarized the history of narcolepsy research in Stanford University. It describes the first observation regarding a temporal association between sleep related disturbances and H1N1 pandemic infection. In 1918, during the influenza pandemia, sleep disturbances and movement disorders as well as extreme sleepiness were noted in flu patients (for more details see [22]). These findings were also supported in the Chinese population after the last pandemic H1N1 influenza. The pandemic infection in China was followed by a parallel increment in the incidence of narcolepsy. The study found 3-4 fold rises in the incidence of narcolepsy in BeijingChina after H1N1 infections [72]. It is noteworthy that in 2011 the incidence of narcolepsy in the Chinese population decreased notoriously returning to the usual incidence $[72,73]$.

The outbreak of the 2009 pandemic influenza led to the fast development and approval of different vaccines resulting in massive immunization campaigns all over the world [4]. In Europe, the use of 8 different commercial vaccines was approved (all designed from the A/California/7/2009 (H1N1) v-like strain). The most widely used was the ASO3-adjuvanted vaccine $[4,74,75]$. Following the 2009 H1N1 vaccination campaing, in 2010 an increment in the diagnosis of narcolepsy in Finish children was noticed [75,76]. This observation led to through deeper epidemiological analysis of the association. In late 2011 the National Institute for Health and Welfare created a task force to determine whether there was a causal relationship between the rise in narcolepsy cases in children from Finland and the 2009 vaccination campaign. The analysis was done comparing the narcolepsy incidence before and after 2009 showing an increased risk of narcolepsy in the 4-19 age group (9-fold) among those who received the ASO3-adjuvanted vaccine,
Pandemrix ${ }^{\mathrm{TM}}$ [77]. Later, the analysis of the individuals infected with the virus show no increased risk of narcolepsy in the overall population [78]. In consequence, the risk of narcolepsy associated with the H1N1 vaccination was evaluated in other countries by retrospective studies based on health care databases and the annual incidence of the disease $[23,76,79-86]$. It is important to mention that in other countries such as Italy and the United Kingdom there was no evidence of increased risk of narcolepsy with Pandemrix ${ }^{\mathrm{TM}}[79]$.

More detailed analyses of some narcolepsy cases linked to the AS03 adjuvanted vaccine have shown interesting characteristics. Slight differences between patients who received or not the vaccine were found in a French study. In particular, vaccinated patients had a shorter delay in diagnosis and the MSLT analysis showed higher number of sleep onset REM periods [86]. Moreover, genotypification of Narcolepsy/Cataplexy post vaccination cases from Switzerland, United States, the United Kingdom, France, and Brazil found that all the patients were carriers of DQB $1{ }^{*} 06: 02$ [61,76,87], and one particular case with an additional diagnosis of multiple sclerosis was also DRB1*15:01 positive [88].

\section{The vaccine dilemma}

Vaccines can be classified within two groups according to their components. The first one is live attenuated vaccines that try to resemble the natural infection. The second group includes subunit, toxoid, carbohydrate, and conjugated vaccines which usually contains adjuvants to enhance and modulate the immune response [89]. In response to the global H1N1 influenza pandemic, both kind of vaccines were design and commercialized [4,74,79]. During the vaccination campaign the vaccines containing squalene based adjuvants were the most used (Table 1 - [80]). Interestingly, in Europe the association between narcolepsy $\mathrm{H} 1 \mathrm{~N} 1$ vaccinations was specifically related to the ASO3 (Pandemrix ${ }^{\mathrm{TM}}$ ) and not to the MF59 adjuvanted vaccine $\left(\right.$ Focetria $\left.^{\circledR}\right)[4,23]$.

\section{The manufacturing process hypothesis}

There is no evidence of narcolepsy in other adjuvanted or nonadjuvanted H1N1 vaccines [90-93]. Just one case has been reported

Table 1

Commercial H1N1 vaccines authorized for 2009 pandemic by the European Center for Disease Prevention and Control or Helath Canada discussed in this review.

\begin{tabular}{|c|c|c|c|c|c|c|}
\hline Name & Producer & Components & $\begin{array}{l}\text { Haemagglutinin } \\
\text { content }(\mu \mathrm{g})\end{array}$ & Adjuvant & Adjuvant Emulsion per dose & $\begin{array}{l}\text { Manufacture inactivation } \\
\text { protocol }\end{array}$ \\
\hline Pandemrix & GSK & $\begin{array}{l}\text { Split-virion, reassortant } \\
\text { A/California/7/2009 (H1N1)v } \\
\text { like strain, inactivated, } \\
\text { Adjuvanted }\end{array}$ & 3.75 & AS03 & $\begin{array}{l}\text { Squalene } 10.69 \mathrm{mg} \\
\alpha \text {-Tocopherol } 11.86 \mathrm{mg} \\
\text { Polysorbate } 804.86 \mathrm{mg}\end{array}$ & $\begin{array}{l}\text { Influenza virus concentration } \\
\text { and purification by zonal } \\
\text { centrifugation using on a linear } \\
\text { sucrose density gradient } \\
\text { solution containing detergent } \\
\text { to split the virus. } \\
\text { Additional purification by } \\
\text { diafiltration } \\
\text { Inactivation by deoxycholeate } \\
\text { and formaldehyde }\end{array}$ \\
\hline Arepanrix & GSK & $\begin{array}{l}\text { Split influenza virus, } \\
\text { A/California/7/2009 (H1N1)v } \\
\text { like strain (X-179A) } \\
\text { inactivated, } \\
\text { Adjuvanted }\end{array}$ & 3.75 & AS03 & $\begin{array}{l}\text { Squalene } \\
10.69 \mathrm{mg} \\
\alpha \text {-Tocopherol } 11.86 \mathrm{mg} \\
\text { Polysorbate } 804.86 \mathrm{mg}\end{array}$ & $\begin{array}{l}\text { Influenza virus inactivation by } \\
\text { UV followed by formaldehyde } \\
\text { Purification by centrifugation } \\
\text { and disruption by } \\
\text { deoxycholate (Tween } 80 \text { ) }\end{array}$ \\
\hline Focetria & Novartis & $\begin{array}{l}\text { Surface-antigens } \\
\text { (haemagglutinin and } \\
\text { neuraminidase), reassortant } \\
\text { A/California/7/2009 } \\
\text { (H1N1)vlike strain, inactivated }\end{array}$ & 7.5 & MF59C.1 & $\begin{array}{l}\text { Squalene } \\
9.75 \mathrm{mg} \\
\text { Polysorbate } 801.175 \mathrm{mg} \\
\text { Sorbitan trioleate } 1.175 \mathrm{mg}\end{array}$ & \\
\hline
\end{tabular}

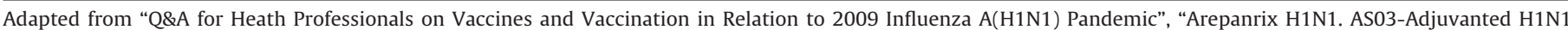
Pandemic Influenza Vaccine” and “Association of receipt of Pandemrix ${ }^{\mathrm{TM}}$ and narcolepsy in children and adolescents in the UK (England) (ECDC 2009-2013, GSK, 2009) GSK: GlaxoSmithKline 
in Brazil, where a 19 year old women carrier of the DQB1*06:02 allele developed narcolepsy after she was vaccinated with Arepanrix (AS03 adjuvanted vaccine manufactured in Canada - Table 1) $[4,87]$. Recently, the hypothesis that the manufacturing process of the vaccines can be the culprit of this situation has been emerged, since they vary in composition as well as in the production process (Table 1) [4,23].

This theory has been discussed since the risk of narcolepsy is associated with Pandemrix ${ }^{\mathrm{TM}}$ but not with Arepanrix ${ }^{\mathrm{TM}}$ or other H1N1 vaccines [90]. Lately, the first two epidemiological studies in Canada were published $[94,95]$. The vaccine used during the vaccination campaign after the $2009 \mathrm{H} 1 \mathrm{~N} 1$ pandemic was Arepanrix ${ }^{\circledR}$ which differs from Pandemrix ${ }^{\mathrm{TM}}$ in the place and the protocol of manufactured (Table 1) [4,23]. In agreement with previous results the analysis done in Ontario did not find any risk associated with the vaccine. Briefly, 1604 adverse events were reported following the immunization, 5 cases went to clinical verification but none of them were consistent with narcolepsy [94]. Likewise, the results in Quebec reported a small risk mainly in persons less than 20 years of age. However, the authors claim that influenza infection could be a confounding factor [95]. All this together suggests that the different protocols employed during the inactivation and the splitting of the virion can influence the final conformation of the immunogenic viral proteins within the vaccine. Therefore, these changes may be reflected in slight modifications in the epitopes that are potentially recognized by $\mathrm{T}$ or $\mathrm{B}$ cells in genetically susceptible individuals $[4,23,96]$.

\section{ASO3 adjuvant and the $\alpha$-tocopherol hypothesis}

The analysis of clinical and epidemiological results of MF-59 did not find any risk of narcolepsy $[97,98]$. Worth mentioning, the major difference between the ASO3 and the MF59 adjuvants is the presence of the $\alpha$-tocopherol (Table 1 ). The adjuvant MF59 induces the expression of cytokines and chemokines by muscle cells at the injection place in mice model resulting in the migration of immune cells including monocytes and granulocytes, especially neutrophils [99]. In consequence, the interaction between these cells amplifies the immune signal improving the antigen processing as well as the transportation to regional lymph nodes. This whole process results in the enhancement of cellular immune response [98-100]. In contrast, the ASO3 adjuvant contains $\alpha$-tocopherol which is a form of vitamin $\mathrm{E}$. The immunomodulator activity of this molecule promotes the innate immune system activation not solely at the injection site but also in non-regional lymph nodes, which makes it more potent in terms of immune system activation. Actually, it was demonstrated that $\alpha$-tocopherol can achieve higher titers and more stable antibody response [101]. Moreover, AS03 modulates the expression of cytokines incrementing the antigen processing and transportation to the lymph nodes, thus leading to enhancement of the antigen-specific adaptive immune response [102,103]. Remarkably, a recent study demonstrated by in vitro analysis that $\alpha$-tocopherol can increase the production of orexin as well as the proteosome activity in a murine hypothalamic cell line. Within the cell, the overproduction of a specific protein is controled, among other by ubiquitination and posterior degradation of the protein in excess. Therefore, this suggested that the overproduction of orexin fragments can conduce to a deregulation of internal cells mechanisms. This may conduce to antigen presentation via HLA, triggering an autoimmune process [104]. However, the authors did not report increment in the expression of HLA molecules leaving an unanswered important aspect. However, all these results may suggest that the differences between vaccine components as well as their manufactured protocol can have an important effect not only in its immunogenic efficiency, but also in the induction of non-specific immune responses and perhaps autoimmunity.
Unfortunately, there are not enough data regarding the differences in the immune reaction to each adjuvant [103].

\section{Conclusions}

Different hypothesis have been proposed to clarify the autoimmune etiology of narcolepsy. Based on these facts we believe that narcolepsy may be an autoimmune disease mainly driven by humoral response. However, the absence of evidence cannot exclude the role cellular response. Autoimmune diseases result from the interaction of 3 factors leading to the clinical manifestations: first inherited factors (i.e. genetics), second environmental factors, and third the breakdown of autoimmune tolerance in particular the appearance of auto-antibodies or auto-reactive T cells. In narcolepsy, the third factor is still unclear. Nevertheless, data are missing regarding the classical criteria for autoimmune diseases. For instance, it is imperative to identify the auto-antigen in order to develop experimental models with active immunization. Therefore, further analyzes on the role of Trib2 and of melaninconcentrating hormone as well as other neural networks are needed to clarify their role in the pathogenesis of the disease.

The association between the H1N1 vaccination or flu infection itself and narcolepsy onset in Europe is well recognized. The epidemiological results showed the importance of geographic location and genetic background. It also raised the concern regarding the effects of vaccines in susceptible individuals. Moreover, it is necessary to homogenize protocols for safety evaluation of vaccines and studies on the effects of adjuvants both on immune system and other physiological processes. This will allow the comparison between components as well as the proper evaluation of the safety. Further follow-up regarding the association with H1N1 vaccination should be done to avoid the induction of the disease in the scenario of future pandemic. Therefore, it is necessary to understand how the manufactured process can alter the H1N1 molecules and the immune system response, as well as if the component of the adjuvant can deregulate neuronal and immune cells.

\section{Competing interests}

Y. Shoenfeld has acted as a consultant for the no-fault U.S. National Vaccine Injury Compensation Program. The other authors declare no competing interests.

\section{Acknowledgments}

The authors express their gratitude to Judy and Stewart Colton for their support.

\section{References}

[1] Shoenfeld Y, Agmon-Levin N. 'Asia' - autoimmune/inflammatory syndrome induced by adjuvants. J Autoimmun 2011;36:4-8

[2] Perricone C, Colafrancesco S, Mazor RD, Soriano A, Agmon-Levin N, Shoenfeld Y. Autoimmune/inflammatory syndrome induced by adjuvants (Asia) 2013: unveiling the pathogenic, clinical and diagnostic aspects. J Autoimmun 2013;47:1-16.

[3] Cohen AD, Shoenfeld Y. Vaccine-induced autoimmunity. J Autoimmun 1996;9:699-703

[4] Ahmed SS, Schur PH, MacDonald NE, Steinman L. Narcolepsy, 2009 A(H1N1) pandemic influenza, and pandemic influenza vaccinations: what is known and unknown about the neurological disorder, the role for autoimmunity, and vaccine adjuvants. J Autoimmun 2014;50:1-11.

[5] Longstreth Jr WT, Koepsell TD, Ton TG, Hendrickson AF, van Belle G. The epidemiology of narcolepsy. Sleep 2007;30:13-26.

[6] Wilner A, Steinman L, Lavie P, Peled R, Friedmann A, Brautbar C. Narcolepsycataplexy in Israeli Jews is associated exclusively with the HLA DR2 haplotype. A study at the serological and genomic level. Hum Immunol 1988;21:15-22.

[7] Al Rajeh S, Bademosi O, Ismail H, Awada A, Dawodu A, Al-Freihi H, et al. A community survey of neurological disorders in Saudi Arabia: the Thugbah study. Neuroepidemiology 1993;12:164-78. 
[8] Akintomide GS, Rickards H. Narcolepsy: a review. Neuropsychiatr Dis Treat 2011;7:507-18

[9] Fontana A, Gast H, Reith W, Recher M, Birchler T, Bassetti CL. Narcolepsy: autoimmunity, effector $\mathrm{T}$ cell activation due to infection, or T cell independent, major histocompatibility complex class II induced neuronal loss? Brain 2010;133:1300-11.

[10] Sakurai T, Mieda M, Tsujino N. The orexin system: roles in sleep/wake regulation. Ann N Y Acad Sci 2010;1200:149-61.

[11] Darien I, editor. International classification of sleep disorders. 3rd ed. American Academy of Sleep Medicine; 2014

[12] Blouin AM, Thannickal TC, Worley PF, Baraban JM, Reti IM, Siegel JM. Narp immunostaining of human hypocretin (orexin) neurons: loss in narcolepsy. Neurology 2005;65:1189-92.

[13] Crocker A, Espana RA, Papadopoulou M, Saper CB, Faraco J, Sakurai T, et al. Concomitant loss of dynorphin, narp, and orexin in narcolepsy. Neurology 2005;65:1184-8.

[14] Thannickal TC, Nienhuis R, Siegel JM. Localized loss of hypocretin (orexin) cells in narcolepsy without cataplexy. Sleep 2009;32:993-8.

[15] Rolls A, Schaich Borg J, de Lecea L. Sleep and metabolism: role of hypothalamic neuronal circuitry. Best Pract Res Clin Endocrinol Metab 2010;24:817-28.

[16] Rose NR, Bona C. Defining criteria for autoimmune diseases (Witebsky's postulates revisited). Immunol Today 1993;14:426-30.

[17] Anaya JM. The autoimmune tautology. Arthritis Res Ther 2010;12:147.

[18] Tanaka S, Honda M, Toyoda H, Kodama T. Increased plasma IL-6, IL-8, TNFalpha, and G-CSF in Japanese narcolepsy. Hum Immunol 2014;75:940-4.

[19] Dauvilliers Y, Jaussent I, Lecendreux M, Scholz S, Bayard S, Cristol JP, et al. Cerebrospinal fluid and serum cytokine profiles in narcolepsy with cataplexy: a case-control study. Brain Behav Immun 2014;37:260-6.

[20] Hong SC, Hayduk R, Lim J, Mignot E. Clinical and polysomnographic features in DQB1*0602 positive and negative narcolepsy patients: results from the modafinil clinical trial. Sleep Med 2000;1:33-9.

[21] Peyron C, Faraco J, Rogers W, Ripley B, Overeem S, Charnay Y, et al. A mutation in a case of early onset narcolepsy and a generalized absence of hypocretin peptides in human narcoleptic brains. Nat Med 2000;6:991-7.

[22] Mignot EJ. History of narcolepsy at Stanford university. Immunol Res 2014:58:315-39.

[23] Partinen M, Kornum BR, Plazzi G, Jennum P, Julkunen I, Vaarala O. Narcolepsy as an autoimmune disease: the role of $\mathrm{H} 1 \mathrm{~N} 1$ infection and vaccination. Lancet Neurol 2014:13:600-13.

[24] Katzav A, Arango MT, Kivity S, Tanaka S, Givaty G, Agmon-Levin N, et al. Passive transfer of narcolepsy: anti-Trib2 autoantibody positive patient IgG causes hypothalamic orexin neuron loss and sleep attacks in mice. J Autoimmun 2013;45:24-30

[25] Smith AJ, Jackson MW, Neufing P, McEvoy RD, Gordon TP. A functional autoantibody in narcolepsy. Lancet 2004;364:2122-4

[26] Cvetkovic-Lopes V, Bayer L, Dorsaz S, Maret S, Pradervand S, Dauvilliers Y, et al. Elevated tribbles homolog 2-specific antibody levels in narcolepsy patients. J Clin Invest 2010;120:713-9.

[27] Lim AS, Scammell TE. The trouble with tribbles: do antibodies against Trib2 cause narcolepsy. Sleep 2010;33:857-8.

[28] Kawashima M, Lin L, Tanaka S, Jennum P, Knudsen S, Nevsimalova S, et al. Anti-tribbles homolog 2 (Trib2) autoantibodies in narcolepsy are associated with recent onset of cataplexy. Sleep 2010;33:869-74.

[29] Kiss-Toth E, Bagstaff SM, Sung HY, Jozsa V, Dempsey C, Caunt JC, et al. Human tribbles, a protein family controlling mitogen-activated protein kinase cascades. J Biol Chem 2004;279:42703-8.

[30] Takasato M, Kobayashi C, Okabayashi K, Kiyonari H, Oshima N, Asashima M, et al. Trb2, a mouse homolog of tribbles, is dispensable for kidney and mouse development. Biochem Biophys Res Commun 2008;373:648-52.

[31] Czibere L, Baur LA, Wittmann A, Gemmeke K, Steiner A, Weber P, et al. Profiling trait anxiety: transcriptome analysis reveals cathepsin B (Ctsb) as a novel candidate gene for emotionality in mice. PLoS ONE 2011;6:e23604.

[32] Bergman P, Adori C, Vas S, Kai-Larsen Y, Sarkanen T, Cederlund A, et al. Narcolepsy patients have antibodies that stain distinct cell populations in rat brain and influence sleep patterns. Proc Natl Acad Sci U S A 2014;111:E3735-44.

[33] Guan JL, Uehara K, Lu S, Wang OP, Funahashi H, Sakurai T, et al. Reciprocal synaptic relationships between orexin- and melanin-concentrating hormone-containing neurons in the rat lateral hypothalamus: a novel circuit implicated in feeding regulation. Int J Obes Relat Metab Disord 2002;26:1523-32.

[34] Rao Y, Lu M, Ge F, Marsh DJ, Qian S, Wang AH, et al. Regulation of synaptic efficacy in hypocretin/orexin-containing neurons by melanin concentrating hormone in the lateral hypothalamus. J Neurosci 2008;28:9101-10.

[35] De la Herran-Arita AK, Kornum BR, Mahlios J, Jiang W, Lin L, Hou T, et al. Cd4+ T cell autoimmunity to hypocretin/orexin and cross-reactivity to a 2009 H1N1 influenza A epitope in narcolepsy. Sci Transl Med 2013;5:216ra176.

[36] De la Herran-Arita AK, Kornum BR, Mahlios J, Jiang W, Lin L, Hou T, et al. Retraction of the research article: Cd4+ T cell autoimmunity to hypocretin/orexin and cross-reactivity to a 2009 H1N1 influenza A epitope in narcolepsy. Sci Transl Med 2014:6:247rt1.

[37] Underwood E. Immunology key narcolepsy-influenza vaccine findings retracted. Science 2014;345:498.

[38] van der Heide A, Verduijn W, Haasnoot GW, Drabbels JJ, Lammers GJ, Claas FH. HLA dosage effect in narcolepsy with cataplexy. Immunogenetics 2014 [Epub ahead of print].
[39] Mignot E, Lin L, Rogers W, Honda Y, Qiu X, Lin X, et al. Complex HLA-DR and -DQ interactions confer risk of narcolepsy-cataplexy in three ethnic groups. Am J Hum Genet 2001;68:686-99.

[40] Kornum BR, Faraco J, Mignot E. Narcolepsy with hypocretin/orexin deficiency, infections and autoimmunity of the brain. Curr Opin Neurobiol 2011;21:897-903.

[41] Hallmayer J, Faraco J, Lin L, Hesselson S, Winkelmann J, Kawashima M, et al. Narcolepsy is strongly associated with the T-cell receptor alpha locus. Nat Genet 2009;41:708-11.

[42] Faraco J, Lin L, Kornum BR, Kenny EE, Trynka G, Einen M, et al. Immunochip study implicates antigen presentation to T cells in narcolepsy. PLoS Genet 2013;9:e1003270.

[43] Winkelmann J, Lin L, Schormair B, Kornum BR, Faraco J, Plazzi G, et al. Mutations in DNMT1 cause autosomal dominant cerebellar ataxia, deafness and narcolepsy. Hum Mol Genet 2012;21:2205-10.

[44] Han F, Lin L, Li J, Aran A, Dong SX, An P, et al. TCRA, P2RY11, and CPT1B/CHKB associations in Chinese narcolepsy. Sleep Med 2012;13:269-72.

[45] Anaya JM. The diagnosis and clinical significance of polyautoimmunity. Autoimmun Rev 2014;13:423-6.

[46] Cardenas-Roldan J, Rojas-Villarraga A, Anaya JM. How do autoimmune diseases cluster in families? A systematic review and meta-analysis. BMC Med 2013;11:73.

[47] Ohayon MM, Okun ML. Occurrence of sleep disorders in the families of narcoleptic patients. Neurology 2006;67:703-5.

[48] Mignot E. Genetic and familial aspects of narcolepsy. Neurology 1998;50:S16-22.

[49] Silber MH, Krahn LE, Olson EJ, Pankratz VS. The epidemiology of narcolepsy in Olmsted county, Minnesota: a population-based study. Sleep 2002;25:197-202.

[50] Nohynek H, Jokinen J, Partinen M, Vaarala O, Kirjavainen T, Sundman J, et al As03 adjuvanted aH1N1 vaccine associated with an abrupt increase in the incidence of childhood narcolepsy in Finland. PLoS ONE 2012; 7:e33536.

[51] Ohayon MM, Ferini-Strambi L, Plazzi G, Smirne S, Castronovo V. How age influences the expression of narcolepsy. J Psychosom Res 2005;59:399-405.

[52] Picchioni D, Hope CR, Harsh JR. A case-control study of the environmental risk factors for narcolepsy. Neuroepidemiology 2007;29:185-92.

[53] Ton TG, Longstreth Jr WT, Koepsell TD. Environmental toxins and risk of narcolepsy among people with HLA DQB1*0602. Environ Res 2010;110:565-70.

[54] Ton TG, Longstreth Jr WT, Koepsell T. Active and passive smoking and risk of narcolepsy in people with HLA DQB1*0602: a population-based case-control study. Neuroepidemiology 2009;32:114-21.

[55] Rose NR. Infection, mimics, and autoimmune disease. J Clin Invest 2001;107:943-4

[56] Kivity S, Agmon-Levin N, Blank M, Shoenfeld Y. Infections and autoimmunity - friends or foes. Trends Immunol 2009;30:409-14.

[57] Sfriso P Ghirardello A, Botsios C, Tonon M, Zen M, Bassi N et al. Infections and autoimmunity: the multifaceted relationship. J Leukoc Biol 2010;87:385-95.

[58] Wucherpfennig KW. Mechanisms for the induction of autoimmunity by infectious agents. J Clin Invest 2001;108:1097-104

[59] Samarkos M, Vaiopoulos G. The role of infections in the pathogenesis of autoimmune diseases. Curr Drug Targets Inflamm Allergy 2005;4: 99-103.

[60] Aran A, Lin L, Nevsimalova S, Plazzi G, Hong SC, Weiner K, et al. Elevated anti-streptococcal antibodies in patients with recent narcolepsy onset. Sleep 2009;32:979-83

[61] Dauvilliers Y, Montplaisir J, Cochen V, Desautels A, Einen M, Lin L, et al. PostH1N1 narcolepsy-cataplexy. Sleep 2010;33:1428-30.

[62] Viorritto EN, Kureshi SA, Owens JA. Narcolepsy in the pediatric population. Curr Neurol Neurosci Rep 2012;12:175-81.

[63] Cunningham MW. Streptococcus and rheumatic fever. Curr Opin Rheumatol 2012;24:408-16.

[64] Commons RJ, Smeesters PR, Proft T, Fraser JD, Robins-Browne R, Curtis N. Streptococcal superantigens: categorization and clinical associations. Trends Mol Med 2014:20:48-62.

[65] Koepsell TD, Longstreth WT, Ton TG. Medical exposures in youth and the frequency of narcolepsy with cataplexy: a population-based case-control study in genetically predisposed people. J Sleep Res 2010;19:80-6.

[66] Snider LA, Swedo SE. Post-streptococcal autoimmune disorders of the central nervous system. Curr Opin Neurol 2003;16:359-65.

[67] Dale RC, Heyman I. Post-streptococcal autoimmune psychiatric and movement disorders in children. Br J Psychiatry 2002;181:188-90.

[68] Dale RC. Post-streptococcal autoimmune disorders of the central nervous system. Dev Med Child Neurol 2005;47:785-91.

[69] Dale RC, Candler PM, Church AJ, Wait R, Pocock JM, Giovannoni G. Neurona surface glycolytic enzymes are autoantigen targets in post-streptococcal autoimmune CNS disease. J Neuroimmunol 2006;172:187-97.

[70] Kirvan CA, Swedo SE, Heuser JS, Cunningham MW. Mimicry and autoantibody-mediated neuronal cell signaling in sydenham chorea. Nat Med 2003;9:914-20

[71] Cox CJ, Sharma M, Leckman JF, Zuccolo J, Zuccolo A, Kovoor A, et al Brain human monoclonal autoantibody from sydenham chorea targets dopaminergic neurons in transgenic mice and signals dopamine D2 receptor: implications in human disease. J Immunol 2013;191:5524-41.

[72] Han F, Lin L, Li J, Dong XS, Mignot E. Decreased incidence of childhood narcolepsy 2 years after the 2009 H1N1 winter flu pandemic. Ann Neurol 2013;73:560 
[73] Han F, Lin L, Warby SC, Faraco J, Li J, Dong SX, et al. Narcolepsy onset is seasonal and increased following the 2009 H1N1 pandemic in China. Ann Neurol 2011;70:410-7.

[74] O'Flanagan D, Cotter S, Mereckiene J. Pandemic A(H1N1) 2009 influenza vaccination survey, influenza season 2009/2010. Vaccine European New Integrated Collaboration Effort (VENICE); 2011.

[75] Kall A. The pandemrix - narcolepsy tragedy: how it started and what we know today. Acta Paediatr 2013;102:2-4.

[76] Zhang X, Penzel T, Han F. Increased incidence of narcolepsy following the 2009 H1N1 pandemic. Somnologie 2013;17:90-3.

[77] THL. National narcolepsy task force interim report, 31 January 2011. Helsinki, Finland: National Institute for Health and Welfare; 2011.

[78] Melen K, Partinen M, Tynell J, Sillanpaa M, Himanen SL, Saarenpaa-Heikkila $\mathrm{O}$, et al. No serological evidence of influenza A H1N1pdm09 virus infection as a contributing factor in childhood narcolepsy after pandemrix vaccination campaign in Finland. PLOS ONE 2013;8:e68402.

[79] Wijnans L, Lecomte C, de Vries C, Weibel D, Sammon C, Hviid A, et al. The incidence of narcolepsy in europe: Before, during, and after the influenza $\mathrm{A}(\mathrm{H} 1 \mathrm{~N} 1) \mathrm{pdm09}$ pandemic and vaccination campaigns. Vaccine 2013;31:1246-54.

[80] Miller E, Andrews N, Stellitano L, Stowe J, Winstone AM, Shneerson J et al. Risk of narcolepsy in children and young people receiving AS03 adjuvanted pandemic A/H1N1 2009 influenza vaccine: retrospective analysis. BMJ 2013;346:f794.

[81] Barker CI, Snape MD. Pandemic influenza A H1N1 vaccines and narcolepsy: vaccine safety surveillance in action. Lancet Infect Dis 2014;14: 227-38.

[82] Eurosurveillance Editorial Team. Swedish medical products agency publishes report from a case inventory study on pandemrix vaccination and development of narcolepsy with cataplexy. Euro Surveill 2011:16.

[83] Bardage C, Persson I, Ortqvist A, Bergman U, Ludvigsson JF, Granath F. Neurological and autoimmune disorders after vaccination against pandemic influenza A (H1N1) with a monovalent adjuvanted vaccine: population based cohort study in Stockholm, Sweden. BMJ 2011;343:d5956.

[84] $\mathrm{DoH}$. Investigation of an increase in the incidence of narcolepsy in children and adolescents in 2009 and 2010 final report of national narcolepsy study steering committee. Iriland: Lenus, the Irish Health Repository; 2012.

[85] Heier MS, Gautvik KM, Wannag E, Bronder KH, Midtlyng E, Kamaleri Y, et al. Incidence of narcolepsy in Norwegian children and adolescents after vaccination against H1N1 influenza A. Sleep Med 2013;14:867-71.

[86] Dauvilliers Y, Arnulf I, Lecendreux M, Monaca Charley C, Franco P, Drouot X, et al. Increased risk of narcolepsy in children and adults after pandemic H1N1 vaccination in France. Brain 2013;136:2486-96.

[87] Mendes MF, Valladares Neto Dde C, Azevedo RA, Caramelli P. Narcolepsy after a/H1N1 vaccination. Clinics (Sao Paulo) 2012:67:77-8.

[88] Vrethem M, Malmgren K, Lindh J. A patient with both narcolepsy and multiple sclerosis in association with pandemrix vaccination. J Neurol Sci 2012;321:89-91.

[89] Pulendran B, Ahmed R. Immunological mechanisms of vaccination. Nat Immunol 2011;12:509-17.
[90] Jefferson T, Rivetti A, Di Pietrantonj C, Demicheli V, Ferroni E. Vaccines for preventing influenza in healthy children. Cochrane Database Syst Rev 2012;8:CD004879.

[91] Jefferson T, Di Pietrantonj C, Rivetti A, Bawazeer GA, Al-Ansary LA, Ferroni E. Vaccines for preventing influenza in healthy adults. Cochrane Database Syst Rev 2014;3:CD001269.

[92] Crucitti A, Tsai TF. Explorations of clinical trials and pharmacovigilance databases of MF59 ${ }^{\circledR}$-adjuvanted influenza vaccines for associated cases of narcolepsy: a six-month update. Scand J Infect Dis 2011;43:993.

[93] Waldenlind L, Grundmark B, Azarbayjani F, Borjesson A, Olaisson H. Is the risk of narcolepsy also increased with non-adjuvanted flu vaccines? BM] 2013;346:f2769.

[94] Harris T, Wong K, Stanford L, Fediurek J, Crowcroft N, Deeks S. Did narcolepsy occur following administration of AS03-adjuvanted A(H1N1) pandemic vaccine in Ontario, Canada? A review of post-marketing safety surveillance data. Euro Surveill 2014:19.

[95] Montplaisir J, Petit D, Quinn MJ, Ouakki M, Deceuninck G, Desautels A, et al Risk of narcolepsy associated with inactivated adjuvanted (AS03) A/H1N1 (2009) pandemic influenza vaccine in Quebec. PLOS ONE 2014;9:e108489.

[96] Miller E, Andrews N, Stellitano L, Stowe J, Winstone A-M, Shneerson J, et al. Association of receipt of pandemrix ${ }^{\mathrm{TM}}$ and narcolepsy in children and adolescents in the UK (England). European Centre for Disease Prevention and Control; 2013.

[97] Choe YJ, Bae GR, Lee DH. No association between influenza A(H1N1)pdm09 vaccination and narcolepsy in South Korea: an ecological study. Vaccine 2012;30:7439-42.

[98] Tsai TF, Crucitti A, Nacci P, Nicolay U, Della Cioppa G, Ferguson J, et al Explorations of clinical trials and pharmacovigilance databases of MF59 ${ }^{\circledR}$ adjuvanted influenza vaccines for associated cases of narcolepsy. Scand J Infect Dis 2011;43:702-6.

[99] Calabro S, Tortoli M, Baudner BC, Pacitto A, Cortese M, O'Hagan DT, et al Vaccine adjuvants alum and MF59 induce rapid recruitment of neutrophils and monocytes that participate in antigen transport to draining lymph nodes. Vaccine 2011;29:1812-23.

[100] O'Hagan DT, Ott GS, De Gregorio E, Seubert A. The mechanism of action of mf59 - an innately attractive adjuvant formulation. Vaccine 2012;30:4341-8.

[101] Walker WT, de Whalley P, Andrews N, Oeser C, Casey M, Michaelis L, et al. H1N1 antibody persistence 1 year after immunization with an adjuvanted or whole-virion pandemic vaccine and immunogenicity and reactogenicity of subsequent seasonal influenza vaccine: a multicenter follow-on study. Clin Infect Dis 2012;54:661-9.

[102] Morel S, Didierlaurent A, Bourguignon P, Delhaye S, Baras B, Jacob V, et al. Adjuvant system AS03 containing alpha-tocopherol modulates innate immune response and leads to improved adaptive immunity. Vaccine 2011;29:2461-73.

[103] Tsai T, Del Giudice G, Crucitti A, Weil J, Narasimhan V. Is the adjuvant solely to blame? BMJ 2013;346:f2375.

[104] Masoudi S, Ploen D, Kunz K, Hildt E. The adjuvant component alphatocopherol triggers via modulation of NRF2 the expression and turnover of hypocretin in vitro and its implication to the development of narcolepsy. Vaccine 2014;32:2980-8. 